\title{
Enhanced decolorization of azo dye in a small pilot-scale anaerobic baffled reactor coupled with biocatalyzed electrolysis system (ABR-BES): A design suitable for scaling-up
}

\author{
Dan Cui ${ }^{\mathrm{a}, 1}$, Yu-Qi Guo ${ }^{\mathrm{c}}$, Hyung-Sool Lee ${ }^{\mathrm{d}}$, Wei-Min Wu ${ }^{\mathrm{e}}$, Bin Liang ${ }^{\mathrm{a}}$, Ai-Jie Wang ${ }^{\mathrm{a}, \mathrm{b}, *}$, Hao-Yi Cheng ${ }^{\mathrm{b}, 1}$ \\ ${ }^{a}$ State Key Laboratory of Urban Water Resource and Environment, Harbin Institute of Technology, No. 202 Haihe, Harbin 150090, PR China \\ ${ }^{\mathrm{b}}$ Key Laboratory of Environmental Biotechnology, Research Center for Eco-Environmental Sciences, Chinese Academy of Sciences, Beijing 100085, PR China \\ ${ }^{\mathrm{c}}$ The Architecture Design and Research Institute of Harbin Institute of Technology, No. 202 Haihe Road, Harbin 150090, PR China \\ ${ }^{\mathrm{d}}$ Department of Civil and Environmental Engineering, University of Waterloo, 200 University Avenue West Waterloo, Ontario N2L 3G1, Canada \\ ${ }^{\mathrm{e}}$ Department of Civil E' Environmental Engineering, Centre for Sustainable Development E Global Competitiveness, Stanford University, Stanford, CA 94305-4020, USA
}

\section{H I G H L I G H T S}

- A pilot-scale refractory wastewater treatment process (ABR-BES) was developed.

- ABR-BES showed superior decolorization performance.

- VFAs could be efficiently utilized for azo dye decolorization in ABR-BES.

- The mechanism of azo dye transformation in ABR-BES was proposed.

- Power supply and HRT were the key impact factors of ABR-BES.

\section{A R T I C L E I N F O}

\section{Article history:}

Received 16 December 2013

Received in revised form 26 March 2014

Accepted 28 March 2014

Available online 13 April 2014

\section{Keywords:}

ABR-BES (anaerobic baffled reactor-

biocatalyzed electrolysis system)

Scale-up

Azo dye wastewater treatment

Power supply

Alizarin yellow R (AYR)

\begin{abstract}
A B S T R A C T
A four-compartment anaerobic baffled reactor (ABR) incorporated with membrane-less biocatalyzed electrolysis system (BES) was tested for the treatment of azo dye (alizarin yellow R, AYR) wastewater (AYR, $200 \mathrm{mg} \mathrm{L}^{-1}$; glucose, $1000 \mathrm{mg} \mathrm{L}^{-1}$ ). The ABR-BES was operated without and with external power supply to examine AYR reduction process and reductive intermediates with different external voltages $(0.3,0.5$ and $0.7 \mathrm{~V})$ and hydraulic retention times (HRT: 8,6 and $4 \mathrm{~h}$ ). The decolorization efficiency in the ABR-BES ( $8 \mathrm{~h}$ HRT, $0.5 \mathrm{~V}$ ) was higher than that in ABR-BES without electrolysis, i.e. $95.1 \pm 1.5 \%$ versus $86.9 \pm 6.3 \%$. Incorporation of BES with ABR accelerated the consumption of VFAs (mainly acetate) and attenuated biogas (methane) production. Higher power supply $(0.7 \mathrm{~V})$ enhanced AYR decolorization efficiency (96.4 $\pm 1.8 \%)$, VFAs removal, and current density $\left(24.1 \mathrm{~A} \mathrm{~m}^{-3} \mathrm{TCV}\right)$. Shorter HRT increased volumetric AYR decolorization rates, but decreased AYR decolorization efficiency.
\end{abstract}

(C) 2014 Elsevier Ltd. All rights reserved.

\section{Introduction}

Biocatalyzed electrolysis systems (BESs) can generate electrical power from organic waste and wastewater, while the power density produced from BESs is too small to be used as renewable power source. Recently, more researches have been focused on wastewater treatment, bioremediation of contaminants and

\footnotetext{
* Corresponding author. Tel./fax: +86 45186282195 (A.-J. Wang).

E-mail addresses: waj0578@hit.edu.cn (A.-J. Wang), chenghaoyihit@126.com (H.-Y. Cheng).

${ }^{1}$ Dr. Cui and Dr. Cheng contributed equally to this paper.
}

stabilization of recalcitrant compounds using BESs to improve cost-effectiveness and sustainability (Mu et al., 2009; Rabaey et al., 2010). Laboratory scale BESs have been successfully tested for the removals of pyridine (Zhang et al., 2009), quinolone (Zhang et al., 2010), indole (Luo et al., 2010), antibiotics ceftriaxone sodium and penicillin (Wen et al., 2011a,b) and 1,2-dichloroethane (Pham et al., 2009) present in wastewater. The main goal of these literatures was to oxidize reduced forms of compounds. In comparison, BESs can be applied to reduce oxidized forms of contaminants on the cathode to less toxic or more stable products. For example, a number of reduction reactions have been achieved using BESs for reducing nitrobenzene (Wang et al., 2011, 2012), antibiotics chloramphenicol (Liang et al., 2013), copper (II) (Tao et al., 2011), 
halogenated compounds (Lohner et al., 2011; Strycharz et al., 2010) and azo dyes (Mu et al., 2009; Cui et al., 2012, 2014). Recently, our research group developed a membrane-less, up-flow biocatalyzed electrolysis reactor (UBER) that successfully reduced azo dye up to $97.5 \pm 1.0 \%$ (Cui et al., 2012, 2014). However, previous studies used acetate as the electron donor for exoelectrogens to generate circuited electrons that were utilized for reducing azo dyes on the cathode in UBER. Since azo dye wastewater contains organics more complex than acetate (Şen and Demirer, 2003), biofilm density of exoelectrogens on the anode was readily diluted by fermenting bacteria in BESs fed with fermentable, complex substrate, and consequently current density could drop seriously (Lee et al., 2008). Then, azo dye reduction on the cathode would be negligible in UBER directly receiving the substrate. UBER would achieve high current density and azo dye reduction efficiency on the cathode if exoelectrogens utilized simple fatty acids and hydrogen gas fermented from complex substrate using dark fermentation or methanogenesis prior to UBER as pre-treatment (Freguia et al., 2008; Hamelers et al., 2010). Such pre-treatment also mitigate the fluctuation of azo dye wastewater quality that often occurred in industrial wastewater.

Anaerobic baffled reactor (ABR) can work efficiently as pretreatment to UBER, due to its several merits. ABR steadily treats recalcitrant wastewater (Barber and Stuckey, 1999). The unique structure of $A B R$ provides separate phases of acidogenesis and methanogenesis in a single reactor, and this phase separation also enhances protection of microorganisms against toxic substances or fluctuation of environmental parameters (e.g., pH, temperature, etc.). Therefore, ABR can improve treatment flexibility to recalcitrant wastewater that is typically fluctuated (Bachmann et al., 1985; Grover et al., 1999). The configuration and operation of ABR are relatively simple over other anaerobic processes, such as the lack of liquid-gas separation devices, packing materials, and mechanical mixing (Metcalf, 2003). Despite of these advantages, ABR would not meet strict effluent standards for recalcitrant wastewater effluent, such as azo dye wastewater, especially at short hydraulic retention time (HRT) (Van der Zee and Villaverde, 2005). The volatile fatty acids (VFAs) produced from fermentation of organics in ABR, especially acetate, are normally poor electron donors for decolorization of azo dyes under anaerobic conditions (Dos Santos et al., 2005, 2007). ABR reduction rate became slow at low concentration of azo dye (less than $40 \mathrm{mg} \mathrm{L}^{-1}$ ) (Bell et al., 2000; Seshadri et al., 1994), and its reduction at low concentration was readily competed with other reduction reactions (Dos Santos et al., 2006). For these reasons, it is challenging to decrease azo dye concentration below textile wastewater discharge standards solely with $A B R$ and post-treatment is needed to further reduce azo dye. Biological aerobic processes would be an option as posttreatment. Intensive aeration with long HRT could remove azo dye enough to meet the standards, but such oxygen supply substantially increases operating and maintenance costs, which significantly dilutes the merits of ABR - lack of oxygen. Taking the advantages of UBER and ABR into account, the combination of the two processes can complement each other. UBER needs a pre-treatment step to generate VFAs as substrate to exoelectrogens, and ABR meets this requirement. ABR cannot reduce azo dye below the discharge standards but UBER can decrease azo dye concentration below the standards without aeration.

In this study, we developed a new system integrating UBER with ABR by installing UBER module into each compartment of ABR (called, ABR-BES) and tested this novel process at a small pilot-scale for the treatment of azo dye (alizarin yellow R: AYR) wastewater. ABR-BES has several advantages for scale-up as compared to existing bio-systems. First of all, ABR-BES is membrane-free system. The lack of membrane can decrease costs for investment and maintenance significantly over other BESs having membrane. Besides, ABR-BES employs low-cost, granular graphite as electrodes without chemical catalysts, which not only increases the contact surface but also reduces capital costs. Moreover, the design of ABR-BES can be readily retrofitted to existing anaerobic wastewater treatment systems, simply with installation of electrodes and baffles in the systems. Therefore, the successful outcomes of this study can facilitate the transfer of this technology into field. This study has three objectives. Firstly, we tracked AYR reduction process, its intermediates, VFAs, and biogases production throughout the compartments of the ABR-BES with and without power supply at a constant HRT of $8 \mathrm{~h}$. Secondly, we tested different applied voltages for AYR reduction at the fixed HRT. Finally, we varied HRT to determine the maximum influent loading rate of AYR at a fixed applied voltage of $0.7 \mathrm{~V}$.

\section{Methods}

\subsection{Anaerobic baffled reactor coupled with biocatalyzed electrolysis system (ABR-BES)}

The schematic diagram of ABR-BES is presented in Fig. 1. ABR-BES was made of PVC (polyvinyl chloride) with external dimensions $\mathrm{L} 80 \mathrm{~cm} \times \mathrm{W} 15 \mathrm{~cm} \times \mathrm{H} 55 \mathrm{~cm}$. The reactor was divided into four compartments (\#1, \#2, \#3 and \#4; the volume of each chamber: $10 \mathrm{~L}$ ) by three straight over-flow plates. The four compartments design of ABR in this study was to improve methane capture by stimulating separate metabolism between fermentation and methanogenesis (Barber and Stuckey, 1999). The over-flow plates have different water levels $(42 \mathrm{~cm}, 40 \mathrm{~cm}$ and $38 \mathrm{~cm}$ in height, respectively), which helped influent flowing from one compartment to the next compartment. Each compartment was separated into an up-flow part and a down-flow part (width ratio of $4: 1$ ) by a vertical baffle (having a $45^{\circ}$ slant edge at the bottom) with a $1 \mathrm{~cm}$ distance from the bottom of the reactor. This configuration allows ABR-BES to have anaerobic granular sludge bed $(\sim 3 \mathrm{~L})$ on bottom and a bioelectrolysis zone in upper portion $(2 \mathrm{~L})$, in individual compartment. As illustrated in Fig. 1, the influent first flowed via anaerobic granular sludge bed at the bottom of compartments where anaerobic biological decolorization reactions would mainly occur. Biocatalyzed electrolysis reactions for decolorizing AYR were simulated in the following. Four samples ports (SP 1\#, SP 2\#, SP 3\# and SP 4\# with inner diagram $1 \mathrm{~cm}$ ) were vertically placed in the ABR-BES for monitoring chemical variation.

The cathode and anode insets in ABR-BES were both made of granular graphite (ID from 3.0 to $5.0 \mathrm{~mm}$, Harbin Northern Electrical Carbon Co., Ltd., China). The graphite was tightly filled in a cuboid basket made up of titanium ( $\mathrm{L} 13 \mathrm{~cm} \times \mathrm{W} 10 \mathrm{~cm} \times \mathrm{H} 7 \mathrm{~cm}$ ) as a current collector. The hole of the basket was rhombic with side of $3 \mathrm{~mm}$. A titanium rod $(30 \mathrm{~cm}$ ) was welded on the basket for electricity conductance and external circuit connection. The anode insets were placed over the cathode in the four compartments. Four $\mathrm{Ag} / \mathrm{AgCl}$ electrodes (+195 V vs standard hydrogen electrode) (Shanghai Precision Scientific Instruments Co., Ltd., China) were installed between the anode and the cathode insets in each compartment to measure electrode potentials. The distances between the reference electrodes and the bottom of the four compartments are $35 \mathrm{~cm}, 34 \mathrm{~cm}, 33 \mathrm{~cm}$ and $32 \mathrm{~cm}$. Electric power was provided to the ABR-BES with a power supply (IT6921, Itech Co., Ltd., USA). The anode and cathode insets, and the reference electrode were connected to a data acquisition system (Keithley 2700, Keithley Co., Ltd., USA) to record electrode potentials and current every $10 \mathrm{~min}$.

Medium was fed into the ABR-BES with a pump (Longer YZII25, Longer pump Co., China) at different flow rates of 87.5-

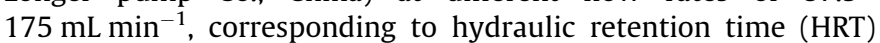
of $8-4 \mathrm{~h}$. 


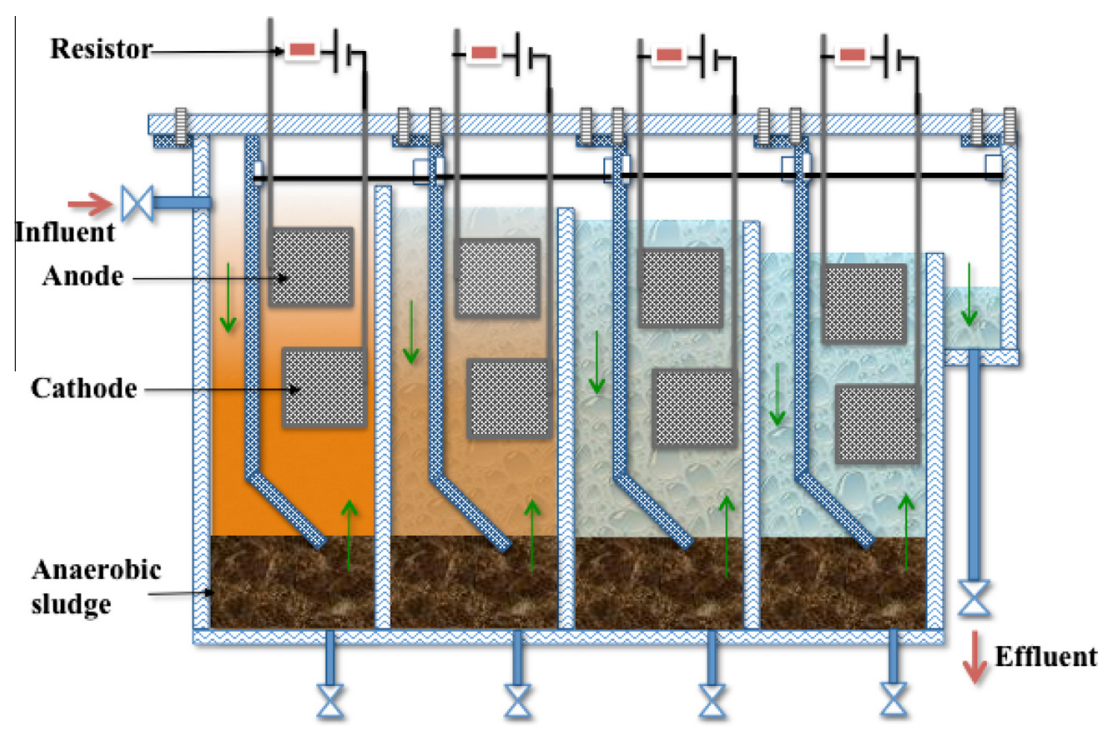

Fig. 1. Schematic of pilot-scale ABR incorporated with BES (ABR-BES). Power was supplied to an individual electrode pair in each compartment of ABR-BES.

\subsection{Inoculation and operational conditions}

The culture of the sludge bed of ABR-BES was inoculated with sludge from a pilot-scale $A B R$ at Shaoxing wastewater plant $\left(50 \mathrm{t} \mathrm{d}^{-1}\right)$, Zhejiang province, China. The VSS/TSS ratio of the sludge was $70 \%$. The culture in ABR-BES was acclimated with glucose medium containing low AYR concentration of $50 \mathrm{mg} \mathrm{L}^{-1}$ for over 90 days. Then, AYR concentration in the medium was stepwise increased up to $200 \mathrm{mg} \mathrm{L}^{-1}$ until ABR-BES showed steady state of AYR removal efficiency at $\sim 70 \%$. Then, we installed the anodes and the cathodes in ABR-BES to evaluate biocatalyzed electrolysis reactions on AYR reduction. Prior to start-up of the ABR-BES, the exoelectrogens on the anodes were inoculated in microbial fuel cells (MFCs) fed with glucose medium as described in the literature (Cui et al., 2012). The inoculum of the anodes in the MFCs was activated sludge collected from Taiping Municipal Wastewater Treatment Plant in Harbin, China. No pre-incubated of cathodes was needed.

Glucose medium was used for ABR-BES and the MFCs contained $\left(\mathrm{L}^{-1}\right)$ : sodium bicarbonate, $3 \mathrm{~g}$; glucose, $1.0 \mathrm{~g}$; AYR, $0.2 \mathrm{~g}$; $\mathrm{NaCl}$, $1.5 \mathrm{~g} ; \mathrm{NH}_{4} \mathrm{Cl}, 0.64 \mathrm{~g}$; yeast extract, $0.1 \mathrm{~g} ; \mathrm{CaCl}_{2}, 0.016 \mathrm{~g} ; \mathrm{FeCl}_{3}$, $0.005 \mathrm{~g} ; \mathrm{K}_{2} \mathrm{HPO}_{4}, 0.067 \mathrm{~g}$; trace element solution, $0.5 \mathrm{~mL}$ and vitamin solution, $0.5 \mathrm{~mL}$ (Donlon et al., 1997). The medium was continuously fed into ABR-BES with a peristaltic pump (BT100 L, Longer Pump Co., Ltd., China). The $\mathrm{pH}$ of the medium was adjusted at $7.0 \pm 0.2$ before feeding it to ABR-BES.

The ABR-BES was operated in six different stages, as shown in Table 1. At stage I, ABR-BES was operated as ABR mode without power supply and bio-electrolysis reactions. At stages II-IV, different voltages $(0.3-0.7 \mathrm{~V})$ were supplied to an individual electrode pair in each compartment of ABR-BES to assess the effect of biocatalyzed electrolysis reactions on AYR reduction at a fixed HRT of $8 \mathrm{~h}$ after pre-inoculated anodes and cathodes were installed in ABRBES (see Fig. 1). Then, AYR reduction was evaluated at different AYR loading rates by decreasing HRT from 8 to 6 and then $4 \mathrm{~h}$ at a constant power supply of $0.7 \mathrm{~V}$ at stages V and VI. All experiments were conducted at $25^{\circ} \mathrm{C}$.

\subsection{Chemicals and analytical methods}

\subsubsection{Chemicals}

Alizarin yellow R (AYR) was commercial purity grade (Shanghai Bioelectrochemical Industry Co., Ltd., China). All other chemicals used were analytical grade.

\subsubsection{Analysis}

Liquid samples taken from ABR-BES were immediately filtered through a $0.22 \mu \mathrm{m}$ filter (Xingya Material Co., Shanghai, China). AYR concentration was measured using a UV-visible spectrophotometer (Shimadzu UV2550, Japan) at a wavelength of $374 \mathrm{~nm}$. The reduced products of AYR were measured by using a high performance liquid chromatography (HPLC, model e2695, Waters Co., USA) equipped with C18 column ( $5 \mu \mathrm{m} ; 5 \times 250 \mathrm{~mm}$, Waters Co., USA). The mobile phase was methanol solution and $0.03 \%$ acetic acid solution with 9:1 ratio ( $\mathrm{vol} / \mathrm{vol}$ ) at a flow rate of $1 \mathrm{~mL} \mathrm{~min}{ }^{-1}$. The detection was performed at $288 \mathrm{~nm}$. Under this analytical condition, the retention time of $p$-phenylenediamine (PPD) and 5aminosalicylic acid (5-ASA) was 2.1 and $3.2 \mathrm{~min}$, respectively. The VFAs were measured using a gas chromatograph (GC, 6890N, Agilent, Inc., USA) equipped with a flame ionization detector, with oven and injector temperatures of 60 and $250{ }^{\circ} \mathrm{C}$, Stabilwax-DA column $(30 \mathrm{~m} \times 0.32 \mathrm{~mm} \times 0.5 \mathrm{~mm})$, and He carrier gas and $\mathrm{N}_{2}$ makeup gas.

Table 1

Operational conditions of different stages.

\begin{tabular}{|c|c|c|c|c|c|c|}
\hline Stage & Time (day) & Reactor & HRT (h) & Power supplied (V) & AYR concentration $\left(\mathrm{mg} \mathrm{L}^{-1}\right)$ & AYR loading rate $\left(\mathrm{g} \mathrm{m}^{-3} \mathrm{~d}^{-1}\right)$ \\
\hline I & $0-90$ & ABR & 8 & No & 200 & 600 \\
\hline II & $91-150$ & ABR-BES & 8 & 0.50 & 200 & 600 \\
\hline III & $151-180$ & ABR-BES & 8 & 0.30 & 200 & 600 \\
\hline IV & $181-210$ & ABR-BES & 8 & 0.70 & 200 & 600 \\
\hline V & $211-240$ & ABR-BES & 6 & 0.70 & 200 & 800 \\
\hline VI & $241-270$ & ABR-BES & 4 & 0.70 & 200 & 1000 \\
\hline
\end{tabular}


The gas produced at each compartment of the ABR-BES was collected using a gasbag (1L Cali-5-Bond, Calibrate, Inc.), and the total volume was measured using a glass syringe. Gas composition was analyzed with a gas chromatograph (GC, 4890D, Agilent, Inc., USA) equipped with a thermal conductivity detector (Lu et al., 2012).

The $\mathrm{pH}$ value was measured using a $\mathrm{pH}$ meter (FE20, Mettler Toledo, Inc. Switzerland vs USA).

\subsubsection{Calculations}

AYR decolorization efficiency (DE, \%) and volumetric decolorization rate (VDR: $\mathrm{mol} \mathrm{m}^{-3} \mathrm{TV} \mathrm{d}^{-1}$ ) were calculated based on the difference between influent and effluent concentrations and total reactor empty volume (TV):

$\mathrm{DE}=\frac{C_{\text {in-AYR }}-C_{\text {ef-AYR }}}{C_{\text {in-AYR }}} \times 100 \%$

$\mathrm{VDR}=\frac{\left(C_{\mathrm{in}-\mathrm{AYR}}-C_{\mathrm{ef}-\mathrm{AYR}}\right) \times Q_{A} \times 1000}{\mathrm{TV}}$

where $C_{\text {in-AYR }}$ is the influent AYR concentration, $\mathrm{mM} ; C_{\text {ef-AYR }}$ is the effluent AYR concentration, $\mathrm{mM} ; Q_{A}$ is the influent flow rate, $\mathrm{m}^{3} \mathrm{~d}^{-1}$; TV is the total reactor empty volume, $\mathrm{m}^{3}$.

Statistical analysis ( $t$-test) was performed using Microsoft Excel 2011 version. The data involved in statistical analysis was collected from individual sampling in each HRT.

The current was calculated from the external resistance based on Ohm's law. The current density based on the cathode volume (CD: $\mathrm{A} \mathrm{m}^{-3} \mathrm{TCV}$ ) was evaluated as follow:

$\mathrm{CD}=\frac{I \times 1000}{\mathrm{TCV}}$

where $I$ is the current $(\mathrm{mA})$; TCV is the total cathode volume $\left(\mathrm{cm}^{-3}\right)$.

\section{Results and discussion}

\subsection{Performance comparison of ABR-BES without and with bio- electrolysis}

\subsubsection{Decolorization efficiency}

Stage I (no bio-electrolysis reactions) lasted 90 days (Table 1 ). During that period, the decolorization efficiency of AYR was $64.9 \pm 11.9 \%$ in the compartment $\# 1$, it was improved by $83.7 \pm 6.5 \%$ in the compartment \#2, and became stable at $85.3-$ $86.9 \%$ in the rest two compartments (Fig. 2A). The AYR decolorization efficiency in each compartment was calculated as accumulated efficiency, which indicated that substantial reduction of AYR occurred in the compartment \#1. The AYR concentration in the final effluent from ABR-BES was $22.4 \pm 7.5 \mathrm{mg} \mathrm{L}^{-1}$ at stage I. At stage II (with $0.5 \mathrm{~V}$ applied voltage), the decolorization efficiency of compartment \#1 and compartment \#2 was $64.9 \pm 1.9 \%$ and $88.9 \pm 1.4 \%$, respectively. It was further improved by $94.2 \pm 1.7 \%$ and $95.1 \pm 1.5 \%$ in the compartments \#3 and \#4, respectively. The improvement of decolorization efficiency in ABR-BES with power supply was significant as compared to that in ABR-BES without power supply ( $t$-test $p=0.0007, n=12$ ), as shown in Fig. 2A. The AYR concentration in the final effluent was as low as $8.9 \pm 1.8 \mathrm{mg} \mathrm{L}^{-1}$, which meets the Chinese Discharge Standard II for textile wastewater. The enhanced decolorization efficiency at stage II implied that biocatalyzed electrolysis reactions did improve decolorization of AYR. In the compartments \#3 and \#4, the AYR concentration declined down to $10.5 \pm 1.3$ and $8.9 \pm 1.8 \mathrm{mg} \mathrm{L}^{-1}$, respectively. Comparing the data from stage I and stage II, it was clear that anaerobic AYR reduction rate using glucose as electron donor would be very slow at low AYR concentration (i.e. in the compartments \#3 and \#4 at stage I), but AYR reduction on the cathodes driven by power supply efficiently occurred even at low AYR concentration (stage II).

Biogas was mainly produced in the compartments \#2 and \#4 in ABR-BES at stage I. Biogas production rates were $149 \pm 13.3 \mathrm{~mL} \mathrm{~h}^{-1}$ $\left(\mathrm{CH}_{4} 55.4 \pm 11.2 \%\right.$ and $\left.\mathrm{CO}_{2} 35.7 \pm 3.1 \%\right)$ and $30.3 \pm 2.7 \mathrm{~mL} \mathrm{~h}^{-1}\left(\mathrm{CH}_{4}\right.$ $58.9 \pm 2.5 \%$ and $\mathrm{CO}_{2} 31.0 \pm 3.1 \%$ ), respectively, for the compartments \#2 and \#4; the volumes of biogas collected in the other compartments were too small to be quantified. Interestingly, biogas generation was trivial in all compartments for stage II. This result supports that exoelectrogens on the anodes outcompeted methanogens (Lee et al., 2008). The $\mathrm{pH}$ in each compartment was very stable at 6.8-7.0 due to high buffer concentration in medium $\left(\mathrm{NaHCO}_{3} 3 \mathrm{~g} \mathrm{~L}^{-1}\right)$.

\subsubsection{VFAs formation}

The major VFAs from glucose fermentation were acetate and propionate, along with negligible amount of butyrate (4$10 \mathrm{mg} \mathrm{L}^{-1}$ ) in ABR-BES. The level of VFAs produced was slightly different between stage I and stage II. As shown in Fig. 2B, at stage I acetate concentration was slightly declined following the sequence of reactor compartments, which was $295.9 \pm 17.5 \mathrm{mg} \mathrm{L}^{-1}$, $287.5 \pm 19.8 \mathrm{mg} \mathrm{L}^{-1}, 249.6 \pm 28.6 \mathrm{mg} \mathrm{L}^{-1}$ and $248.4 \pm 26.2 \mathrm{mg} \mathrm{L}^{-1}$, respectively. In comparison, proportionate concentration was relatively constant in a range of $57.3 \pm 11.4-64.6 \pm 1.9 \mathrm{mg} \mathrm{L}^{-1}$ throughout all compartments. At stage II (at applied voltage $0.5 \mathrm{~V}$ ), the profiles of acetate and propionate along the different compartments were similar to those at stage I: decreasing acetate and relatively constant propionate concentration (in a range of $82.1 \pm 10.2-114.9 \pm 6.3 \mathrm{mg} \mathrm{L}^{-1}$ ) along the compartments. However, acetate removal to the compartments was relatively substantial at stage II, as compared to stage I, which ranged from $288.9 \pm 9.6$ to $150.2 \pm 12.1 \mathrm{mg} \mathrm{L}^{-1}$. This lower acetate concentration indicated that exoelectrogens on the anodes actively might consume acetate for current generation, which was used for AYR reduction at the cathodes. This result accorded well to less methane production and higher AYR reduction in the ABR-BES at stage II than stage I.

Therefore, the electron transfer pathway at stage I and stage II maybe different. At stage I, glucose was fermented to acetate by anaerobic fermentative bacteria mainly in anaerobic sludge. Acetate was further utilized by methanogens to produce methane. AYR was reduced by some azo-reducing bacteria. After electrodes introduced at the stage II, most of acetate was utilized by exoelectrogens as electron donor and methane production became limited.

\subsubsection{Major intermediates of $A Y R$ reduction}

Two major intermediates of PPD and 5-ASA from AYR reduction were observed (Fig. 2C). Relatively higher PPD and lower 5-ASA (ranged from $0.09 \pm 0.007$ to $0.15 \pm 0.003 \mathrm{~mol} \mathrm{~L}^{-1}$ ) concentrations were found in the ABR-BES at stage I than those at stage II. At stag I, PPD concentration was low at $0.4 \pm 0.01 \mathrm{~mol} \mathrm{~L}^{-1}$ in the compartment \#1, increased to $0.6 \pm 0.07 \mathrm{~mol} \mathrm{~L}^{-1}$ in the compartment \#2, and remained constant in the compartments $3 \#$ and \#4. The increase of PPD concentration along the compartments at stage II was slightly lower than that at stage I, i.e. it increased from $0.3 \pm 0.05$ in compartment \#1 to $0.55 \pm 0.03 \mathrm{~mol} \mathrm{~L}^{-1}$ in compartment \#4. However, the accumulation of 5-ASA was relatively substantial at stage II, as compared to stage I, which ranged from $0.21 \pm 0.01 \mathrm{~mol} \mathrm{~L}^{-1}$ to $0.36 \pm 0.03 \mathrm{~mol} \mathrm{~L}^{-1}$.

Stoichiometrically, complete reduction of one mol AYR produces one mole of PPD and one mole of 5-ASA with consumption of $10 \mathrm{~mol}$ electrons via p-nitro-aniline (PNA) as intermediate (Eqs. (4) and (5)):

$\mathrm{AYR}+4 \mathrm{e}^{-} \rightarrow 5-\mathrm{ASA}+\mathrm{PNA}$

$\mathrm{PNA}+6 \mathrm{e}^{-} \rightarrow \mathrm{PPD}$ 

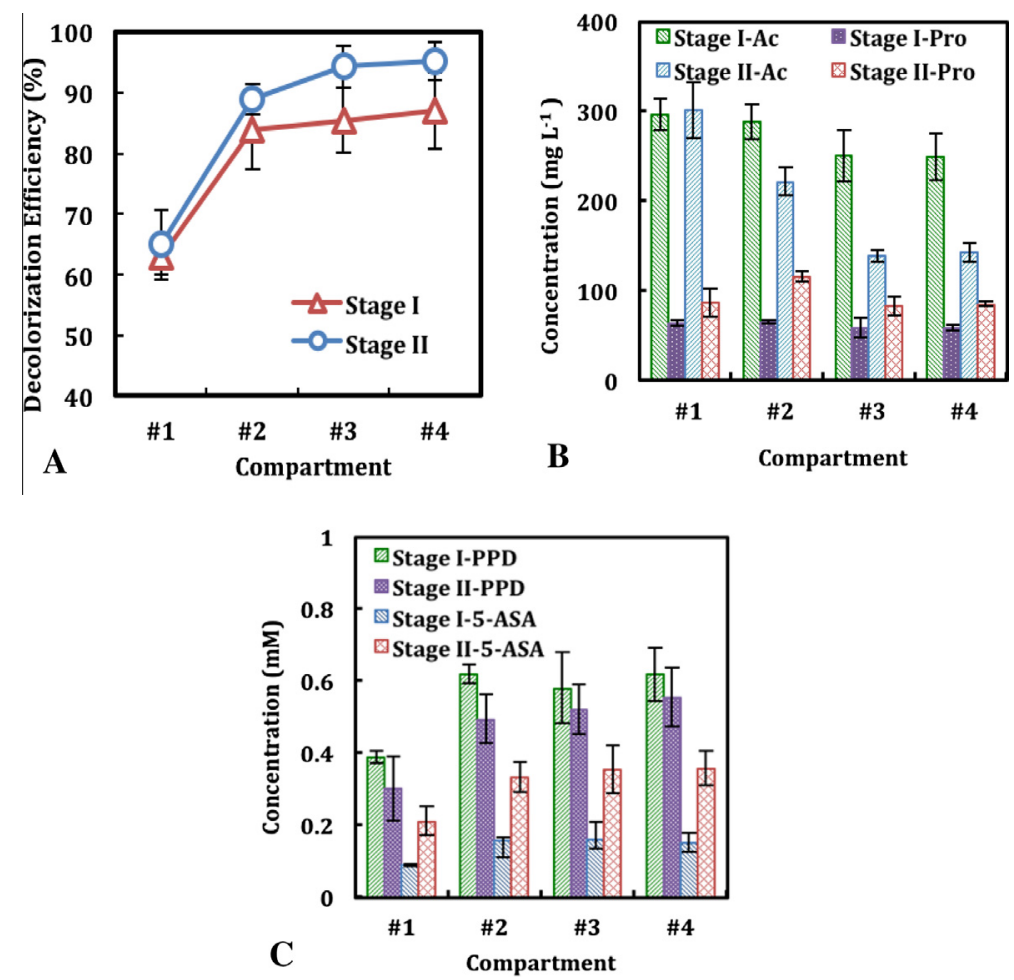

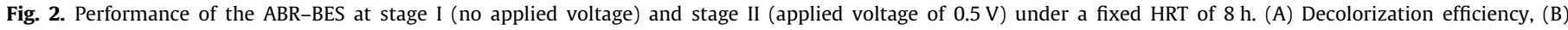
concentrations of volatile acids, and (C) concentrations of PPD and 5-ASA.

This reaction requires $6 \mathrm{~mol} \mathrm{e}^{-}$for the reduction of azo bond $(-\mathrm{N}=\mathrm{N}-)$ and $4 \mathrm{~mol} \mathrm{e}^{-}$for reduction of nitro bond $\left(-\mathrm{NO}_{2}\right)$ in PNA, as described by Kanagaraj and Mandal (2012). Hence, the concentrations of 5-ASA and PPD become equal to the concentration of removed AYR for complete AYR reduction, based on the Eqs. (4) and (5). However, more PPD accumulation than 5-ASA was consistently observed in the ABR-BES at both stage I and stage II. PPD is typically resistant to anaerobic degradation (Donlon et al., 1997; Kanagaraj and Mandal, 2012), while 5-ASA is susceptible for anaerobic degradation via acetogenic fermentation or methanogenesis (Razo-Flores et al., 1997). Such different biodegradability of the two intermediates resulted in the accumulation of more PPD and less 5-ASA in ABR-BES. At stage II, PPD concentration was slightly lower than that at stage I, probably due to PPD oxidation by exoelectrogens on the anodes. Interestingly, relatively high accumulation of 5ASA was observed at stage II, which supports the lack of anaerobic microorganisms (e.g., acetogenic fermenters and methanogens) for 5-ASA. We did not find measurable amount of methane production at stage II, but observed methane production at stage I.

\subsection{Performance of ABR-BES at different voltage supplied}

To examine the effect of power supply on the performance of ABR-BES (stages III and IV), the external power was changed from $0.5 \mathrm{~V}$ to $0.3 \mathrm{~V}$ and then increased to $0.7 \mathrm{~V}$ (Table 1 ). Fig. 3A showed that decolorization efficiency of AYR in each compartment was improved with the increase of applied voltage. The highest decolorization efficiency was $96.4 \pm 0.8 \%$ at applied voltage of $0.7 \mathrm{~V}$. In the compartments \#1 and \#2, the decolorization efficiencies were nearly the same under the three voltage conditions, while they obviously increased at high voltages in compartments \#3 and \#4. This result consistently indicated more active bioelectrochemical reactions in the latter compartments having low AYR concentrations (from 10.4 to $7.4 \mathrm{mg} \mathrm{L}^{-1}$ ). We used $t$-test to investigate whether the voltage made significant difference in AYR decolorization. Comparing the decolorization efficiency of ABR-BES between $0.3 \mathrm{~V}$ and $0.5 \mathrm{~V}$ applied voltage, the $p$ values $(n=12)$ were 0.04 for compartment \#3 and 0.05 for compartment \#4. They were 0.01 and 0.008 for compartment \#3 and compartment \#4, respectively, at applied voltage $0.7 \mathrm{~V}$. All p values were much lower than 0.05 , indicating that AYR decolorization in the compartments \#3 and \#4 was remarkably enhanced at higher applied voltage.

High applied voltage also improved the degradation of acetate and propionate in ABR-BES (Fig. $3 B$ and C). Acetate concentration decreased rapidly along the compartments in comparison with the experiments with lower voltages. At applied voltage of $0.7 \mathrm{~V}$, acetate concentrations were $275.2 \pm 8.2 \mathrm{mg} \mathrm{L}^{-1}, \quad 212.9 \pm 17.1 \mathrm{mg} \mathrm{L}^{-1}$, $97.5 \pm 17.1 \mathrm{mg} \mathrm{L}^{-1}$ and $83.7 \pm 11.8 \mathrm{mg} \mathrm{L}^{-1}$, respectively, along the compartments \#1 to \#4. Propionate decreased along the reactor compartments was not as obvious as acetate trend, but less propionate concentration was found in latter compartments at high applied voltages (Fig. 3C). It seemed that propionate would be degraded to acetate and hydrogen by acetogenic bacteria and both products were utilized for current generation (Cha et al., 2010). More substrate removal (mainly acetate and propionate) meant higher current density, which improved AYR reduction on the cathodes. The average current density of the four compartments increased from $10.1 \pm 0.6$ to $23.7 \pm 1.6 \mathrm{~A} \mathrm{~m}^{-3} \mathrm{TCV}$ with increasing applied voltage $(0.3-0.7 \mathrm{~V})$ (Fig. 3D). There was little difference of current density in the compartments \#2 to \#4, while low current density was consistently observed in the compartment \#1. The results suggested that the contribution of biocatalyzed electrolysis reactions on AYR reduction would be relatively substantial in the compartments \#2 to \#4 where VFAs were primary substrates. The biocatalyzed electrolysis reactions would not be required for AYR reduction in the compartment \#1 due to active anaerobic AYR reduction using glucose as electron donor. We found similar AYR reduction at $0.5 \mathrm{~V}$ and $0.7 \mathrm{~V}$ of applied voltage, although higher 

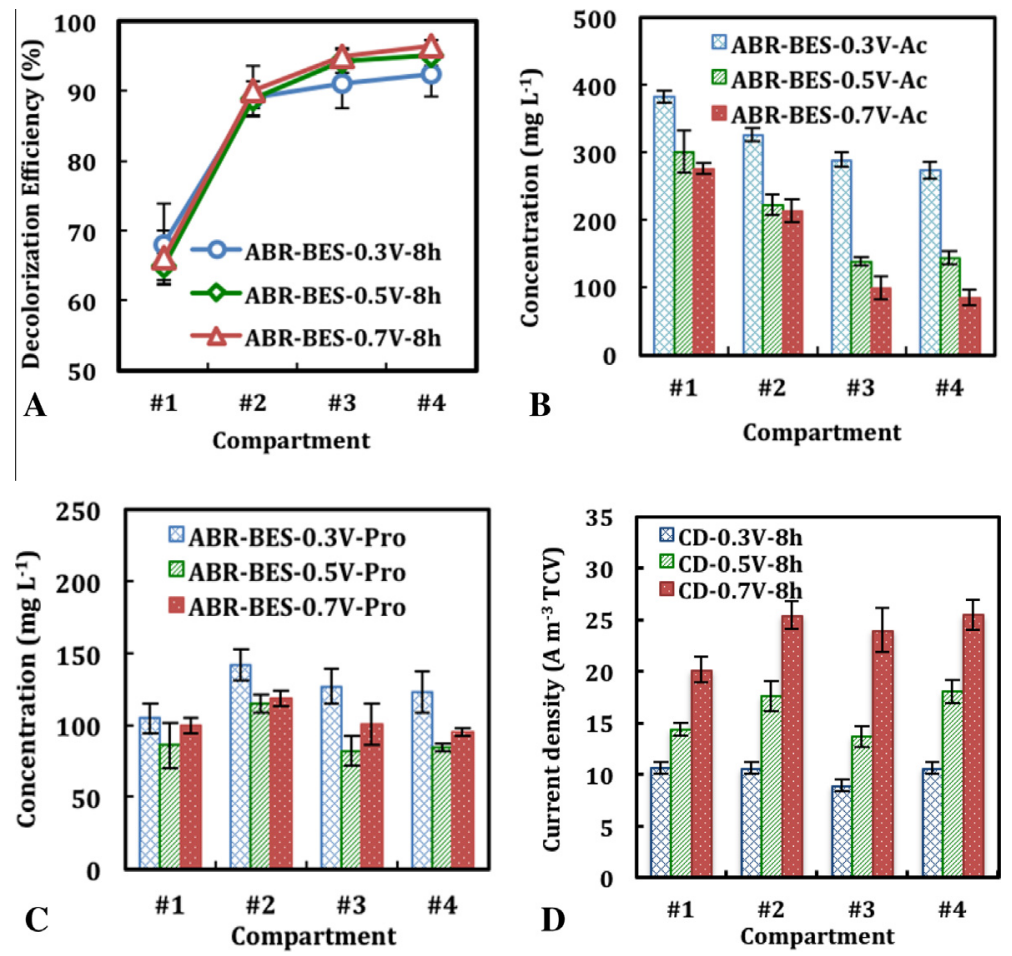

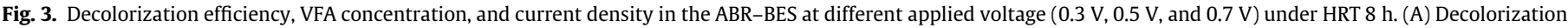
efficiency, (B) acetate concentration, (C) propionate concentration, and (D) current density per total cathode volume (TCV).

applied voltage improved current density significantly. It may be due to that at low AYR concentration, the effect of applied voltage on AYR reduction efficiency was not strong enough due to kinetics, and the protons could be reduced to form hydrogen gas on the cathodes.

\subsection{Performance of ABR-BES at different HRTs}

At the stages IV, V and VI, we examined the performance of ABR-BES at three different HRTs ( $8 \mathrm{~h}, 6 \mathrm{~h}$, and $4 \mathrm{~h}$ ) with a constant applied voltage of $0.7 \mathrm{~V}$. Decolorization efficiency of AYR decreased
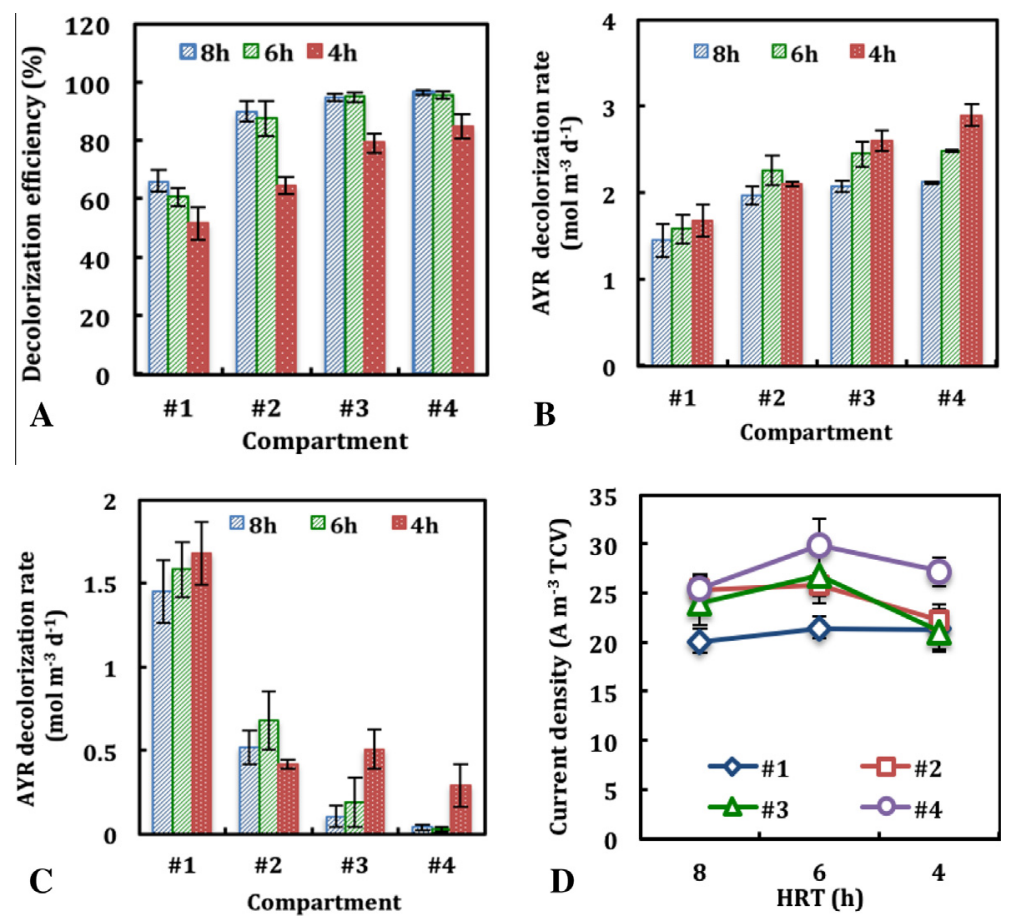

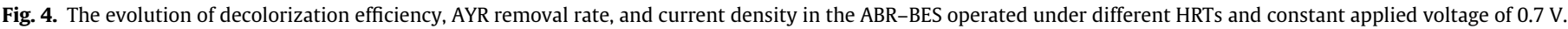
(A) Decolorization efficiency; (B) cumulative AYR removal rate, (C) AYR removal rate for each compartment, and (D) current density per total cathode volume (TCV). 
as HRT declined (AYR loading rate increased). It was $96.4 \pm 1.8 \%$, $95.7 \pm 1.2 \%$ and $84.8 \pm 1.7 \%$, respectively, for HRT of $8 \mathrm{~h}, 6 \mathrm{~h}$ and $4 \mathrm{~h}$ (Fig. 4A). The majority of AYR was decolorized in the compartment \#1, as the same as observed in previous experiments. The decline of AYR decolorization efficiency with short HRT or high AYR loading rate indicated that biocatalyzed electrolysis reduction of AYR had kinetically limited. The relationship between the cumulative volumetric decolorization rate (VDR) of AYR increased with decreasing HRT (increasing AYR loading rate) was shown in Fig. 4B. VDR increased from $2.12 \pm 0.02 \mathrm{~mol} \mathrm{~m}^{-3} \mathrm{~d}^{-1}$ to $2.90 \pm 0.13 \mathrm{~mol} \mathrm{~m}^{-3} \mathrm{~d}^{-1}$ at HRT decreasing from 8 to $4 \mathrm{~h}$, which implied that AYR reduction either via glucose fermentation or biocatalyzed electrolysis reactions depends on AYR loading rate. Fig. 4C showed the AYR decolorization rate in individual compartments. The volumetric AYR removal rate increased with increasing AYR loading rate, except for the compartment \#2, indicating that the influent AYR loading rate first reached the treatment limitation of compartment \#2 at HRT of $6 \mathrm{~h}$. Relatively high AYR decolorization rate in the compartments \#3 and \#4 at HRT 4 h supported consistent biocatalyzed electrolysis reduction of AYR in these compartments, which was observed in other experiments (Figs. 2 and 3). High current density in the compartment \# 3 $\left(26.7 \pm 2.8 \mathrm{~A} \mathrm{~m}^{-3} \mathrm{TCV}\right)$ and \#4 $\left(29.8 \pm 2.7 \mathrm{~A} \mathrm{~m}^{-3} \mathrm{TCV}\right)$ also supported active biocatalyzed electrolysis reduction of AYR in the latter compartments (Fig. 4D), while HRT variation did not influence current density much. Due to the limitation of decolorization efficiency and the effluent discharge quality, HRT of $6 \mathrm{~h}$ was likely the most suitable for ABR-BES operation.

\section{Conclusion}

The decolorization efficiency of AYR was significantly improved in ABR-BES with electrolysis in comparison with ABR-BES without electrolysis. Higher power supplied $(0.7 \mathrm{~V})$ led to higher AYR decolorization efficiency $(96.4 \pm 1.8 \%)$ and current density $\left(24.1 \mathrm{~A} \mathrm{~m}^{-3}\right.$ TCV). The volumetric removal rate of AYR in ABR-BES increased as HRT decreased from 8 to $4 \mathrm{~h}$, but the decolorization efficiency of AYR was decreased. The optimal operational condition with highest current density was obtained at HRT of $6 \mathrm{~h}$ and $0.7 \mathrm{~V}$ power supplied. The novel ABR-BES with membrane-free provided a new concept for BES scaling-up to energy-efficient treatment of azo dye wastewater.

\section{Acknowledgements}

This research was supported by the National Natural Science Foundation of China (NSFC, Grant Nos. 51078100 and 31370157), by National Science Foundation for Distinguished Young Scholars (Grant No. 51225802), by Science Fund for Creative Research Groups of the National Natural Science Foundation of China (Grant No. 51121062), by the National High-tech R\&D Program of China (863 Program, Grant No. 2011AA060904), by The Ph.D. Programs Foundation of Ministry of Education of China (20102302110055), by "Hundred Talents Program" of the Chinese Academy of Sciences, and By State Key Laboratory of Urban Water Resource and Environment. HIT (Grant No. 2013DX02). Dr. Wei-Min Wu was a Guest Professor of Harbin Institute of Technology.

\section{References}

Bachmann, A., Beard, V.L., McCarty, P.L., 1985. Performance characteristics of the anaerobic baffled reactor. Water Res. 19 (1), 99-106.

Barber, W.P., Stuckey, D.C., 1999. The use of the anaerobic baffled reactor (ABR) for wastewater treatment: a review. Water Res. 33 (7), 1559-1578.
Bell, J., Plumb, J.J., Buckley, C.A., Stuckey, D.C., 2000. Treatment and decolorization of dyes in an anaerobic baffled reactor. J. Environ. Eng. 126 (11), 1026-1032.

Cha, J., Choi, S., Yu, H., Kim, H., Kim, C., 2010. Directly applicable microbial fuel cells in aeration tank for wastewater treatment. Bioelectrochemistry 78 (1), 72-79.

Cui, D., Guo, Y.Q., Cheng, H.Y., Liang, B., Kong, F.Y., Lee, H.S., Wang, A.J., 2012. Azo dye removal in a membrane-free up-flow biocatalyzed electrolysis reactor coupled with an aerobic bio-contact oxidation reactor. J. Hazard. Mater. 239240, 257-264.

Cui, D., Guo, Y.Q., Lee, H.S., Cheng, H.Y., Liang, B., Wang, A.J., 2014. Effect of cathode size and HRT on azo dye removal in an up-flow biocatalyzed electrolysis reactor coupled with an aerobic bio-contact oxidation reactor (UBER-ABOR). Chem. Eng. J. 243, 355-363.

Dos Santos, A.B., Madrid, M.P., Stams, A.J.M., Van Lier, J.B., Cervantes, F.J., 2005. Azo dye reduction by mesophilic and thermophilic anaerobic consortia. Biotechnol. Prog. 21 (4), 1140-1145.

Dos Santos, A.B., Madrid, M.P., de Bok, F.A.M., Stams, A.J.M., Van Lier, J.B., Cervantes, F.J., 2006. The contribution of fermentative bacteria and methanogenic archaea to azo dye reduction by thermo-philic anaerobic consortium. Enzyme Microb. Technol. 39 (1), 38-46.

Dos Santos, A.B., Cervantes, F.J., Van Lier, J.B., 2007. Review paper on current technologies for decolourisation of textile wastewaters: perspectives for anaerobic biotechnology. Bioresour. Technol. 98, 2369-2385.

Donlon, B., Razo-Flores, E., Luijten, M., Swarts, H., Lettinga, G., Field, J., 1997. Detoxification and partial mineralization of the azo dye mordant orange 1 in a continuous upflow anaerobic sludge-blanket reactor. Appl. Microbiol. Biotechnol. 47 (1), 83-90.

Freguia, S., Rabaey, K., Yuan, Z., Keller, J., 2008. Syntrophic processes drive the conversion of glucose in microbial fuel cell anodes. Environ. Sci. Technol. 42 (21), 7937-7943.

Grover, R., Marwaha, S.S., Kennedy, J.F., 1999. Studies on the use of an anaerobic baffled reactor for the continuous anaerobic digestion of pulp and paper mill black liquors. Process Biochem. 34 (6), 653-657.

Hamelers, H.V., Ter Heijne, A., Sleutels, T.H., Jeremiasse, A.W., Strik, D.P., Buisman, C.J., 2010. New applications and performance of bioelectrochemical systems. Appl. Microbiol. Biotechnol. 85 (6), 1673-1685.

Kanagaraj, J., Mandal, A.B., 2012. Combined biodegradation and ozonation for removal of tannins and dyes for the reduction of pollution loads. Environ. Sci. Pollut. Res. 19, 42-52.

Lee, H.S., Parameswaran, P., Kato-Marcus, A., Torres, C.I., Rittmann, B.E., 2008 Evaluation of energy-conversion efficiencies in microbial fuel cells (MFCs) utilizing fermentable and non-fermentable substrates. Water Res. 42 (6), 1501 1510 .

Liang, B., Cheng, H.Y., Kong, D.Y., Gao, S.H., Sun, F., Cui, D., Kong, F.Y., Zhou, A.J., Liu, W.Z., Ren, N.Q., Wu, W.M., Wang, A.J., Lee, D.J., 2013. Accelerated reduction of chlorinated nitroaromatic antibiotic chloramphenicol by biocathode. Environ. Sci. Technol. 47 (10), 5353-5361.

Lohner, S.T., Becker, D., Mangold, K.M., Tiehm, A., 2011. Sequential reductive and oxidative biodegradation of chloroethenes stimulated in a coupled bioelectroprocess. Environ. Sci. Technol. 45 (15), 6491-6497.

Luo, Y., Zhang, R., Liu, G., Li, J., Li, M., Zhang, C., 2010. Electricity generation from indole and microbial community analysis in the microbial fuel cell. J. Hazard. Mater. 176 (1), 759-764.

Lu, L., Xing, D., Ren, N., 2012. Pyrosequencing reveals highly diverse microbial communities in microbial electrolysis cells involved in enhanced $\mathrm{H}_{2}$ production from waste activated sludge. Water Res. 46 (7), 2425-2434.

Metcalf, I.N.C., 2003. Wastewater Engineering; Treatment and Reuse. McGraw-Hill.

Mu, Y., Rabaey, K., Rozendal, R.A., Yuan, Z., Keller, J., 2009. Decolorization of azo dyes in bioelectrochemical systems. Environ. Sci. Technol. 43 (13), 5137-5143.

Pham, H., Boon, N., Marzorati, M., Verstraete, W., 2009. Enhanced removal of 1,2dichloroethane by anodophilic microbial consortia. Water Res. 43 (11), 2936 2946.

Rabaey, K., Butzer, S., Brown, S., Keller, J., Rozendal, R.A., 2010. High current generation coupled to caustic production using a lamellar bioelectrochemical system. Environ. Sci. Technol. 44 (11), 4315-4321.

Razo-Flores, E., Luijten, M., Donlon, B.A., Lettinga, G., Field, J.A., 1997. Complete biodegradation of the azo dye azodisalicylate under anaerobic conditions. Environ. Sci. Technol. 31 (7), 2098-2103.

Seshadri, S., Bishop, P.L., Agha, A.M., 1994. Anaerobic/aerobic treatment of selected azo dyes in wastewater. Waste Manage. (Oxford) 14 (2), 127-137.

Sen, S., Demirer, G.N., 2003. Anaerobic treatment of real textile wastewater with a fluidized bed reactor. Water Res. 37 (8), 1868-1878.

Strycharz, S.M., Gannon, S.M., Boles, A.R., Franks, A.E., Nevin, K.P., Lovley, D.R., 2010 Reductive dechlorination of 2-chlorophenol by Anaeromyxobacter dehalogenans with an electrode serving as the electron donor. Environ. Microbiol. Rep. 2 (2) 289-294.

Tao, H.C., Liang, M., Li, W., Zhang, L.J., Ni, J.R., Wu, W.M., 2011. Removal of copper from aqueous solution by electrodeposition in cathode chamber of microbial fuel cell. J. Hazard. Mater. 189 (1), 186-192.

Van der Zee, F.P., Villaverde, S., 2005. Combined anaerobic-aerobic treatment of azo dyes - a short review of bioreactor studies. Water Res. 39 (8), 14251440.

Wang, A.J., Cheng, H.Y., Liang, B., Ren, N.Q., Cui, D., Lin, N., Rabaey, K., 2011. Efficient reduction of nitrobenzene to aniline with a biocatalyzed cathode. Environ. Sci. Technol. 45 (23), 10186-10193. 
Wang, A.J., Cui, D., Cheng, H.Y., Guo, Y.Q., Kong, F.Y., Ren, N.Q., Wu, W.M., 2012. A membrane-free, continuously feeding, single chamber up-flow biocatalyzed electrolysis reactor for nitrobenzene reduction. J. Hazard. Mater. 199, 401-409.

Wen, Q., Kong, F., Zheng, H., Cao, D., Ren, Y., Yin, J., 2011a. Electricity generation from synthetic penicillin wastewater in an air-cathode single chamber microbial fuel cell. Chem. Eng. J. 168 (2), 572-576.

Wen, Q., Kong, F., Zheng, H., Yin, J., Cao, D., Ren, Y., Wang, G., 2011b. Simultaneous processes of electricity generation and ceftriaxone sodium degradation in an air-cathode single chamber microbial fuel cell. J. Power Sources 196 (5), 25672572.

Zhang, C., Li, M., Liu, G., Luo, H., Zhang, R., 2009. Pyridine degradation in the microbial fuel cells. J. Hazard. Mater. 172 (1), 465-471.

Zhang, C., Liu, G., Zhang, R., Luo, H., 2010. Electricity production from and biodegradation of quinoline in the microbial fuel cell. J. Environ. Sci. Health Part A 45 (2), 250-256. 